\title{
Comment: Ethnography under arrest?
}

\author{
By Alberto Corsín Jiménez (CSIC - Spanish National Research Council)
}

The image with which Shannon Morreira opens her article is arresting, literally and figuratively: an activist who, challenged to write a slogan for a street protest, suddenly sinks in hesitation, and asks aloud, 'What do I write?' A 'moment of silence', Morreira tells us, was 'followed by a plethora of answers' (Morreira, page 1). The silence, the arrest, captures beautifully the violence of knowledge: the precariousness and hubris through which knowledge is called to arms.

The arrest of knowledge, however, is violent in more ways than one. Brush in hand, the activist is arrested for words when pondering how to describe the human rights violations to which asylum seekers are exposed. Arrest, however, is also what immigrants face if their applications are deemed 'unfounded' and their stay in the country is therefore sanctioned illegal. Arrest here amounts to a real threat of detention: being asked to produce evidence for the state, if we find ourselves lost for (the appropriate legal) words, we run the risk of losing our (state) personhood too. It would seem that 'arrest' is the condition of personhood that state knowledge puts forth into existence.

If the state weighs in on knowledge of human rights through the pressure of arrest, Morreira's Shona informants lay their emphasis instead on their rightful duty to 'keep together'. 'I am also fulfilling my [human] rights', tells Morreira one of her informants, 'if I am trying to keep my family.' It is people's mutual recognition of their duty of care that informs their sense of dignity. To fall short of such reciprocal or relational acknowledgements is tantamount to an 'infringement of human rights' (Morreira, page 7). The rights-bearing person must be at one with the company of her acknowledgements.

In a somewhat different fashion, arrest and acknowledgement may also be seen at work in Laura Mateos' article on the travels of intercultural discourse. The category of interculturality, as Laura tells us, has become common currency in policy-making and academic debate: universities, government agencies and NGOs have learnt to do interculturality in education, public health or immigration programmes. There are of course 'cultural divergences' in the uses of the term, reflecting the biographical and sociological trajectories of various actors. Administrative staff from the Department of Indigenous Education of the Veracruz State Ministry, for example, are unlikely to use the term in the same way as an 'ideologue' (say, a university professor) from the Universidad Veracruzana Intercultural (Mateos Cortés, page 4). They both speak of interculturality, but interculturality does different work for each.

Thus, among government workers, interculturality seems to reproduce arresting and paralysing notions of indigenous cultural participation. In the words of one of her informants, it veers towards a 'folkloristic view of culture, generates stereotypes and 
emphasises differences' (Mateos Cortés, page 7). Academics, on the other hand, seem keener to look for acknowledgement-relations: here interculturality is deployed to 'promote... the ability to reciprocally recognise the diversity that exists with an emphasis on hybrid and interactive aspects' (Mateos Cortés, page 7). Notwithstanding, investment in interculturality is always fragile, and both academics and policy-makers, when setting out to put interculturality to work - when engaged in the 'process of transferring', as Laura puts it, interculturality between 'transmitters and 'receivers' - are prone to encounter 'reactions of resistance [that] can serve to avoid the process of transfer, while reaffirming the implied actor's own identity' (Mateos Cortés: 6). Both as a knowledge-form (an object of policy), and a relational experience (the reciprocal recognition of hybrid educational experiences), interculturality therefore runs the risk of arrestment.

Arrest and acknowledgement are not of course counterpoints. Some experiences of arrest may be read instead as attempts to hold in suspension the frenzy of everyday life so we can better comprehend our surrounding field of relational acknowledgements. We make the world come to a stand-still so that its relational field comes in full view. An occasion, perhaps, to indulge in the description of arresting acknowledgements.

In a philistine rant against creativity (understood as a call to arms to produce ever new knowledge), Thomas Osborne has built on Andrew Barry's distinction between 'inventiveness' and the categories of novelty and speed (Barry 2000), to suggest that unlike creativity, which builds on some negative notion of 'inertia' for its own traction, inventiveness may be 'in part made up of a certain kind of inertia' (Osborne 2003: 520). This is the inertia of description.

According to Osborne, inventiveness emerges out of the reassembling configuration of problems: when problem-solving becomes not so much an exercise in identifying solutions, as an exercise in ongoing problematisation; a never-ending routine of work 'into, around and away from the problem, the point of maximum inertia' (Osborne 2003: 521). Inventiveness, in other words, is hard work because it entails churning out ever different descriptions of the same problem. With every new description comes an 'acknowledgement' of a different arrangement of activities, objects, actors and processes (Osborne 2003: 522). ${ }^{1}$ They amount, perhaps, to the same problem, but the shifting field of acknowledgements enables and opens up a new mode of problematisation. Thus, if inventiveness and inertia are indeed related in situations of knowledge-making, there may be some use for 'arresting acknowledgements' in the description of their relatedness. Between the inventive and the inertial hangs therefore in suspension (in parenthetical arrest) the moment of description of their mutual acknowledgement.

\footnotetext{
1 'What looks like inertia for some comes to a more objective, later generation as evidence of a breakthrough. And what may seem like a breakthrough can come to seem just like further inertia when viewed from a later more objective perspective. So, in the terms given currency by Stanley Cavell, it is precisely acknowledgement rather than knowledge that is the only orientation we can take towards inventiveness itself' (Osborne 2003: 521-522, emphasis in the original).
} 
The moment of parenthetical arrest between inventiveness and inertia is poignantly captured by Natalie Konopinski in her piece. In response to the 'impact' revolution taking hold of the academy today, social scientists are rushing to incorporate new audiovisual and social media technologies that may help position them in the appropriate 'pathways to impact'. But as Natalie observes, the very routing of knowledge through so-called pathways is going to have epistemic consequences for all: 'Such activities as disseminating ideas and showing fieldwork in action using podcasts and website discussion taps into new forms of contemporary ethnography and various ways in which this recent focus on KE [knowledge exchange] may impact our ideas of ethnography and the ethnographer' (Konopinski, page 5). Having to resort to new technologies and modalities of fieldwork will no doubt provoke inventive rearrangements of the ethnographic project. But it will call too for understanding the parallel reconfiguration of its moments of inertia: for a start, 'translating these forms and methods of ethnography into the language of impact and KE discourses expected for grant applications' (Konopinski, page 5).

The language of impact is 'anticipatory' and 'potential', full of 'perhaps' (Konopinski, page 7). Who knows: the pathways may eventually fork and 'knowledge' and 'exchange' part ways. Perhaps the terms of identification of users and usage, benefit and beneficiaries, or community and stakeholders turn up to be challenged and undermined by the research itself. Confronted with a grant application prompt to identify impact, the ethnographer's perplexity thus reminds us of Shannon Morreira's street protester: 'What do I write?' What, indeed, to write?

There is, it seems, a moment of description pending, between the knowledge and the exchange, were ethnography is lost for words. Ethnography under arrest. The anthropologist thereafter searches for an ethnographic register that may help explicitate and acknowledge the relations that knowledge and exchange have to one another. A language that would enable each to 'take care' of the other (Strathern 2010: 10-11). A language of arresting acknowledgements.

To the language of impact, then, perhaps anthropology can offer as an alternative the language of acknowledgements. What if we were to describe the output of our research as an instantiation of its 'acknowledgements'? What kind of research object / concept would an anthropological acknowledgement look like?

I doubt this enterprise would find ethnography lost for words.

\section{About the Author}

Alberto Corsín Jiménez is Senior Scientist at the Spanish National Research Council. He has carried out fieldwork in the nitrate communities of the Atacama Desert, Chile; among innovation management consultants in Buenos Aires; and more recently, among "prototyping" communities of digital artists, media activists and academics at a Medialab in Madrid. A forthcoming book is provisionally titled, Anthropological baroques: an essay on the political optics of modernity. 


\section{Bibliography}

Barry, A. (2000), 'Invention and Inertia', Cambridge Anthropology, 21, 62-70.

Osborne, T. (2003), 'Against "Creativity": A Philistine Rant', Economy and Society, $32,507--525$.

Strathern, M. (2010), 'A Tale of Two Letters. Reflections on Knowledge Conversions', Insights 3, 1-15. 